\title{
A luta de Jacó COM o Anjo: O CRÍTICO ENTRE 0 GOZO E 0 TEXTO MÓVEL DO MANUSCRITO
}

\author{
PHILIPPE WILLEMART \\ Universidade de São Paulo
}

Comentando o quadro de Delacroix de 1861, A luta de Jacob com o Anjo ${ }^{1}$, proponho uma reflexão sobre a maneira de ler o manuscrito.

Vejamos o texto bíblico:

E levantou-se aquela mesma noite, e tomou as suas duas mulheres, e as suas duas servas, e os seus onze filhos, e passou o vau de Jaboque.E tomou-os e fê-los passar o ribeiro; e fez passar tudo o que tinha. Jacó, porém, ficou só; e lutou com ele um homem, até que a aurorachegou. E vendo este que não prevalecia contra ele, tocou a juntura de sua coxa, e se deslocou a juntura da coxa de Jacó, lutando com ele. E disse: Deixa-me ir, porque já a aurora chegou. Porém ele disse: Não te deixarei ir, se não me abençoares. E disse-lhe: Qual é o teu nome? E ele disse: Jacó. Então disse: Não te chamarás mais Jacó, mas Israel; pois como príncipe lutaste com Deus e com os homens. E Jacó lhe perguntou, e disse: Dá-me, peço-te, a saber o teu nome. E disse: Por que perguntas pelo meu nome? E abençoou-o ali. E chamou Jacó o nome daquele lugar Peniel, porque dizia: Tenho visto a Deus face a face, e a minha alma foi salva. E saiu-lhe o sol, quando passou a Peniel; e manquejava da sua coxa. ${ }^{2}$

Luta desigual por um lado, um deus contra um homem, mas que não termina. No final da noite, não há vencedor. Jacó fica com uma ferida na anca que o fez mancar, recebe uma benção e ganha um nome novo: Israel, que significa "Forte contra Deus". Mas não saberá o nome daquele contra quem ele lutou.

1. Como entender a aproximação entre esta luta e o leitor do manuscrito? Onde está o crítico? Deus ou Jacó?

Henry Bauchau,que gostava bastante deste quadro, ajudará na resposta:

Em frente à Luta com o Anjo de Delacroix, perguntei-me onde está meu lugar atual. É a vertigem, abalando minhas fundações que me indicam este lugar. Devo lutar com ele e ficar na reserva de maneira a entender o que ele tem que me dizer. Estar ao mesmo tempo em Jacó e no Anjo não esquecendo que estou velho agora embora ainda seja uma criança. Preciso renunciar à maravilhosa segurança de cada um dos dois lutadores para ficar o mais perto possível do que há entre eles. O mais importante, é a luta com o Anjo, é o espaço entre combatentes. Não sou este espaço, sou nele. ${ }^{3}$ 
Nem anjo nem Jacó, o escritor Bauchau deve recolher a força que emana dos dois protagonistas para escrever. Mas como fazê-lo? Continuar lutando, não vencer o adversário para ter tempo de ouvir a mensagem que não é escrita. Os adversários se tocam físicamente, se veem, se ouvem e atingem a psique através das pulsões, este conceito de Freud no qual se junta o físico e o psíquico e que envolve o olhar, a voz, o tocar e o ouvir. Segundo Lacan, as pulsões são "o eco no corpo do fato que há um dizer". ${ }^{4}$

O dizer numa luta não é necessariamente uma palavra articulada, mas reúne também os gritos, os resmungos, os suspiros emitidos pelos adversários nos seus esforços para vencer. Podemos evocar o shofar, este som do corne do carneiro que lembra a Aliança entre Deus e Israel, maneira de apaziguar a angústia inerente à vida humana. ${ }^{5}$

Dizer significa que a palavra deve ser ouvida. Todas as pulsões precisam da palavra que vai do barulho até a palavra articulada para agarrar-se a um corpo. A pulsão invocante seria a pulsão mãe ao redor da qual giram as outras e lembra a voz de Deus ${ }^{6}$, ou em termos psicanalíticos, a voz do grande Outro.

O olhar e o imaginário que decorre dele, não vem em primeiro lugar. Como a criança no útero escuta primeiramente antes de nascer, como os combatentes, o Anjo e Jacó, lutando na obscuridade da noite, ouvem-se primeiramente, assim o crítico debruçado no manuscrito deve atravessar sua leitura para ouvir ressoar o texto nele. Voltarei ao assunto.

Por outro lado, um psicanalista inglês ousou dizer que "somos cavalgados pela pulsão".7 Assim como o cavalo é dominado pelo cavaleiro, assim somos submetidos às pulsões e contrariamente ao que acreditamos, somos muito pouco autônomos.

Onde está esta força invocante na roda da escritura? Ela está no centro e coordena os cinco movimentos como mostra a imagem ao lado. Chamei-a texto móvel, o que associa um grão de gozo - as pulsões gozam, e vou detalhá-las - com um texto móvel.

Lembremos, em primeiro lugar, o que é o grão de gozo e o texto móvel.

O escritor não escreve sem um prazer particular que o empurra a trabalhar, prazer muitas vezes misturado com sofrimento como as rasuras testemunham, mas este prazer/sofrimento está sempre sustentado por um gozo inconsciente que chamei, grão de gozo, que tem na sua base a pulsão invocante. Dar um sentido ao grão de gozo desconhecido é o objetivo subentendido e não sabido de todo escritor. O texto móvel é o texto rasurado questionado em cada releitura até o texto publicado.

Nós, leitor do texto ou do manuscrito, procuramos também por nossa crítica saber em que o texto nos agradou e dar um sentido a nosso prazer embora soframos bem menos do que o escritor. Somos também empurrados por um texto móvel quando escrevemos. No entanto, ler um texto publicado não é ler um manuscrito como sabemos.

Antes de nosso esforço de compreensão do sentido pela inteligência, nossa primeira atitude não deveria ser, uma atitude de escuta benevolente, que deriva da pulsão invocante quando lemos um texto literário? Não se trata somente de ouvir um passado que gozou, como Lacan sugere, fazendo um trocadilho: jouis! (goza) ou j'ouis (escuto), algo ou alguém que gozou no passado. É preciso ir mais longe, seguindo nisso Roberto Zular, na sua análise do poema Esboço de uma serpente, de Valéry. ${ }^{8}$ É preciso ouvir nossa própria voz transformada pelo texto lido. Tanto quanto Eva não deve ouvir somente a voz da serpente, mas além, ouvir sua própria voz atraída pelas promessas da serpente que desprezam as de Deus. 
Mas quando leio um manuscrito, devo escutar minha própria voz através da do autor? Não temos que lutar contra a escritura e suas rasuras, entendê-la e transcrevê-la? Deste trabalho de deciframento, trabalhoso para Proust, mais tranquilo para Bauchau e Renato Castelo, não é primeiramente uma luta contra a língua quando, cegado pelo Anjo ou pela força da narrativa, procuro vencê-lo para reencontrar o som ou o sentido rasurado na forma? Lá está nosso sofrimento como crítico.

Esta mudança de perspectiva, como leitor do manuscrito e não mais como leitor de um livro publicado, me obriga sem dúvida a mudar algo nos movimentos já definidos da rodada leitura ${ }^{9}$ e a encarar a diferença ao nível do interesse que ponho. Não procurarei mais conhecer especificamente uma história e saber o fim, não estarei envolvido pelas personagens nem dilacerado entre eles para saber de que lado me situo, meu afeto não se deixará levar em primeiro lugar pelo imaginário do romance que me separa do mundo no qual vivo. O romance já foi lido e somente será considerado como o fim de um longo processo ou de uma longa caça do escritor preso com a história e sua língua.

Ainda, posso falar da rodada leitura? Seguirei as etapas que parecem tão claras?

Abrimos um fólio de Flaubert, de Proust, de Bauchau ou de Renato Castelo. Somos surpreendidos pelas formas pouco habituais de uma página de livro, a tal ponto que certos críticos como Almuth Grésillon,compararam uma sequência de fólios a uma obra de arte. Entretanto, atrás desta beleza aparente, se beleza há, se esconde um trabalho enorme que pode acabar em tragédia, já que a simples releitura do escritor pode abalar o trabalho de horas, até mesmo de dias.

Estarei frente a uma escritura não linear por excelência, cheia de rasuras, de volta para trás, de acréscimos nas margens de cima, de baixo, dos dois lados, como se o escritor não soubesse o que ele quer no início, como se hesitasse antes de escrever, ou melhor, como se fosse a presa de um outro ou do Outro a qual se submete. É a primeira coisa que observamos quando lemos um manuscrito, a luta do escritor com alguém de poderoso que o obriga a rever continuamente seu texto, luta que lembra a de Jacó com o Anjo, da qual falei no início e que tanto inspirou Henry Bauchau. Não somente o escritor belga se vê no espaço de luta entre Jacó e o Anjo e manipula o Anjo para saber mais, mas num segundo movimento, ele reconhece o Anjo e o nomeia:

Um herói persiste em nossa época: o inconsciente. Se aceitamos lutar com ele, é a luta com o anjo. Saímos da luta fértil, reforçado mas machucado como Jacó-Israel. ${ }^{10}$

Pouco importa se chamarmos este adversário ou este colaborador Anjo, grande Outro, grão de gozo ou inconsciente, mas sua presença me obriga a considerá-los e a me perguntar quais são os meios de intervenção. Saibamos, entretanto, que não se trata da musa do movimento romântico que faz do escritor um puro instrumento da voz ouvida independentemente do que ele é nem da musa no sentido grego do termo que, filha de Zeus e de Mnemosine, serve de intermediária entre artistas e os deuses.

Este colaborador da escritura, semelhante em certos pontos a Mnemosine, pela memória de fatos datados, e à musa romântica, porque exige um obediência cega, é mais uma voz gozadora (agradável e sofrida) que, se impondo ou dialogando com o escritor, o acorda, o faz percorrer caminhos inéditos e ancorar-se tanto no Real (o que é difícil traduzir em palavras) no qual se banha o escritor quanto no Real da comunidade que o cerca. Esta voz se faz escutar no 
terceiro movimento da roda da escritura e está ligada especialmente ao texto móvel colocado no centro da roda da escritura.

Mas na leitura do manuscrito, voltamos ao nosso assunto, não tratarei com o texto móvel, mas com um texto fixo, embora muitas vezes rasurado sob o qual corre sempre o grão de gozo que me interpelará.

Se vejo a manifestação evidente do texto móvel no manuscrito através das rasuras, eu me percebo igualmente movido pelo Anjo, o grande Outro ou o inconsciente, representado pelo grão de gozo que me empurrou na escolha e na leitura do manuscrito. É neste nível que dialogarei com o manuscrito, sabendo ou não. Não poderei intitular minha leitura, do grão de gozo do escritor para o texto móvel do escritor, mas do grão de gozo do escritor para o meu. Um diálogo se estabelecerá necessariamente e muitas vezes sem eu saber entre os grãos de gozo que subentenderam aquele que formou a escritura e aquele que me encorajou a estudar o manuscrito.

Fora este diálogo, inconsciente a maioria do tempo, como me deixar levar ou como devo colaborar neste diálogo?

Como crítico genético, e supondo que a escritura é legível e já decifrada, tento entender não mais a história que já conheço, mas a maneira com a qual é construída o texto. É a mesma pulsão invocante adubada da pulsão de saber que me leva à leitura do livro publicado, mas diferentemente eu me prendo a palavras, a frases e à sintaxe e me adentro em seguida como se estas palavras formassem um túnel no qual eu me enfio para pegaras maneiras de ressoar, as ranhuras, os suportes e os alicerces.

Mas, não se trata de um túnel qualquer? O narrador proustiano descreveu um ideal de escuta quando apresentou a personagem Swann ouvindo a pequena música de Vinteuil. Sua alma se deixava amoldar pela melodia e « passava sozinha no corredor, no filtro obscuro do som». ${ }^{11}$ A leitura em voz alta do manuscrito chegará raramente neste ponto, mesmo quando inteiramente decifrado. As superposições de rasuras, as voltas para trás ou as remissões impediriam de escutar uma linha de som encantadora para o leitor.

No entanto, a leitura em voz alta do texto rasurado e decifrado pode revelar sons inéditos ou uma melodia suprimida que me leva a um espaço-tempo insuspeitado.

O ritmo 2/7 da primeira frase da Busca do Tempo Perdido que se afirma aos poucos nos manuscritos parece prioritário embora não esteja sabido do escritor na constituição da frase:

Longtemps 2

je $\mathrm{m}^{\prime}[\mathrm{e}]$ suis couché de bonne heure. 7

Parfois, 2

à peine ma bougie éteinte, 7

mes yeux se fermaient si vite 7

que je n'avais pas le temps 7

de me dire « je m'endors $» .7$

Et une demi-heure après, $7 .{ }^{12}$ 
Uma cadência se deixou ouvir que lembra não a Aliança entre Deus e Israel evocada pelo shofar, mas o pacto primordial, embora muitas vezes esquecido ou ignorado, que amarra cada escritor à música, à cadência e ao ritmo. É uma das teses que sustento centrando a roda da escritura na pulsão invocante.

Como escreve Hermann Broch nos Sonâmbulos, a música dá uma liberdade mais alta que solta os laços terrestres levando "a ordem e a unidade no embaralhamento e a condição caótica da vida. ${ }^{13}$ A melodia parece nestas condições o fundamento de qualquer atividade artística e humana.

Da onde vem a pulsão escópica que continua me movendo, embora esteja associada à do saber ligada ela mesma a das origens? Não me contento mais em me deixar levar pelo texto para saber o fim da história, mas paro frequentemente, ou o texto me para, tendo em vista a dificuldade de leitura.

Por quê? Por vários motivos. Primeiramente, porque tenho o texto publicado na cabeça. Embora seja um resultado aleatório e não necessário do manuscrito, devo considerá-lo já que faz parte da identidade de quem assina, o autor. O texto publicado me dá uma orientação ou me mostra uma lógica sem dúvida não linear, mas que não está ligada forçosamente ao manuscrito que leio.

Quantos textos do narrador proustianos foram abandonados e teriam suscitado uma outra escritura ou mesmo outra história? A descoberta de um manuscrito inédito nos arquivos de Suzy Mante-Proust, sobrinha de Marcel Proust permitiu a Nathalie Mauriac de editar uma outra Albertine disparue ${ }^{14}$ mais curta do que a versão lançada por Robert Proust e Jacques Rivière nas edições Gallimard. A riqueza do manuscrito assusta neste sentido, me leva além do texto publicado e me questiona sobre o salto que suprimiu ou esqueceu tal trecho.

Flaubert também inventou uma história do povo judeu no manuscrito de Hérodias que manteve apenas numa frase. Bauchau escreveu uma história da Virgem Maria para o romance Dilúvio que suprimiu a pedido do editor.

$\mathrm{O}$ manuscrito me para também porque me remeto à uma tradição de escritura e de inserção na cultura presente tanto na produção do autor quanto na de seus contemporâneos e antecessores. Escutar, prestar atenção e me colocar na espreita lendo o manuscrito me ajudará a encontrar um vestígio ou um rastro do enigma que se constrói aos poucos, graças a uma aproximação formal de sons, de palavras, de frases ou a uma associação de ideias. Estarei na posição do narrador proustiano que, pelo odor de fumaça, o sabor da madeleine ou o barulhão de um guardanapo engomado, reencontrava um passado esquecido e podia rearticular a narrativa.

$\mathrm{Eu}$, como crítico abandonarei então a roda da leitura e, levado à escritura, pularei na roda da escritura, saída normal para o crítico. No entanto, antes de chegar lá, a aproximação inesperada poderá abalar meus pontos de referência habituais e me fará encontrar outros. É o quarto movimento da roda, aquele que cria inconvenientes/embarras ${ }^{15}$ e talvez coisas inquietantes. ${ }^{16}$

Temos um exemplo no fólio 18 do caderno 28 de Marcel Proust:

Porque o dia em que vimos no Louvre um quadro de Chardineque temos entendemos sua significação,o gênio de Chardin liberado [...] em virtude desta fecundidade incalculável das obras de arte ela se espalha em nós, e inumeráveis são os Chardin que nos apresenta cada dia nossa modesta sala de jantar na qual não cansamos de ver um 
início de raio de sol mandar passar por tons intermediários entre o terno e o brilhante as dobras da toalha e o relevo da faca que a desposa. ${ }^{17}$

A ligação entre a iluminação pelo sol da sala de jantar e o gênio de Chardin abalará os pontos de referências habituais do crítico. Não observarei minha sala de jantar com o mesmo olhar e tentarei pegar os Chardin que me cercam e que ignorava. Para chegar lá, eu me servirei de outras redes para explicar o enigma do que leio e do mundo que me cerca e me sentirei deslocado em relação a minha situação anterior. Guiado por esta nova rede, alusão à obra de Cecília Almeida Salles ${ }^{18}$, a leitura do manuscrito terá, ela também mudada, e estará à espreita de outras descobertas, e me encorajará a continuar a leitura.

No entanto, não estarei liberado tão facilmente. Assim como Jacó sairá da luta ferido e mancando, eu não sairei de minha leitura indemne. Terei sido tocado senão ferido, eu também. Não me chamarei por isso Israel ou forte contra Deus como Jacó, mas mais humildemente, forte contra a escritura lida da qual terei levantado um dos sentidos ou um dos velos da enigma escrevendo um artigo ou um livro durante ou após minha leitura.Terei assim caracterizado o autor contrariamente a Jacó, que não saberá o nome do Anjo.

Uma vez flaubertiano, proustiano, baucheliano ou casteliano, levarei a marca no meu estilo e minha maneira de pensar a escritura e a literatura, meu grão de gozo terá cruzado um daqueles do escritor e a rodada leitura-escritura continuará a girar nem sem ter mudado o quinto movimento que me levará em outras redes.

Será que respondi às perguntas do início? Nos sentimos no lugar de Jacó quando lutamos para decifrar, entender, ouvir o manuscrito ou somos como o Anjo resistindo à força de Jacó ou à do escritor? Nem um nem outro inteiramente.

Supondo que o Anjo represente a criação e a perfeição entre aspas do texto publicado, portanto, que ele enclausure o conjunto dos manuscritos para chegar à última versão assinada pelo autor, primeiramente, lutamos contra uma escritura mais ou menos difícil de ler, transcrevemos uma língua que tem uma história extremamente rica na qual as palavras e as expressões têm variado de sentido no decorrer da história.

Em segundo lugar, nos chocamos com uma lógica mutante ou com arranjo de situações e de personagens que se modificam seguindo o avanço da história. Qualidades atribuídas a uma personagem são transpostas em outra como Hérodias e Antipas no conto Hérodias de Flaubert, por exemplo, ou o músico Vinteuil, que reúne qualificações do naturalista Vingtone do músico Berge $^{19}$ na BTP, etc.

Como a luta dos dois protagonistas é sem fim a ponto do Anjo impor um limite e pedir a Jacó que ele o largue" porque a aurora chegou", assim é a pesquisa. A luz revelaria a natureza do Anjo? Metaforicamente falando, a obscuridade dos manuscritos ou o acúmulo de acréscimos e de rasuras é favorável à procura dos processos de criação. Clareza demais ou evidência demais, como o texto publicado ou um rascunho "limpo", nos desviaria da verdadeira pesquisa ancorada nas pulsões.Embora a transcrição possa nos dar a ilusão de que estamos no fim, as leituras sucessivas nos levarão a escutar cada vez mais diferentemente o manuscrito transcrito. Nunca, senão raramente, chegaremos ao fim do enigma.

Somos também o Anjo de vez em quando, aquele que, detendo o sentido do texto publicado ou que acreditando o deter, luta com Jacó para não revelar nem seu nome nem o último sentido? O Anjo representa a perfeição no sentido de que nunca chegaremos a uma 
interpretação final. E se acreditamos pegar o todo ou demos uma interpretação dita definitiva, é que a obra é ruim segundo o poeta inglês John Ashbery: "mais sua arte é ruim, mais é fácil falar dela". ${ }^{20}$ Com efeito, há sempre mais coisas para descobrir na leitura do manuscrito. $\mathrm{O}$ exercício da pulsão invocante é sem fim para as boas obras.Mas a aurora chegou e preciso parar...

\section{Notas de fim}

1 Vários artistas representaram a cena: Rembrandt em 1659, Gustave Doré em 1855, Gustave Moreau em 1878, Eugène Delacroix (igreja Saint-Sulpice, Paris) em 1861, Paul Gauguin em 1888, Maurice Denis em 1893, Odilon Ređon em 1910, René Iché (coll. Centre Pompidou e Musée Fabre) em 1942, Chagall em vários vitrais.

${ }^{2}$ Gênesis 32:21-32

${ }^{3}$ Bauchau, Henry. Jour après jour. Journal d'Edipe sur la route (1983-1989), pp. 19-20

${ }^{4}$ Lacan, Jacques. O seminário. Livro 23, O sinthoma, Rio, Zahar, 2007, p. 18

5 "A função do chofar entra em ação em certos momentos periódicos que se apresentam, à primeira vista, como renovacão do pacto da Aliança. […] O momento médio das três emissôes solenes do chofar, ao cabo dos dias de jejum do Rosh ha-Shna, que se chama Zikkaron - ao passo que a espécie de tremolo que é característica de uma certa maneira de tocar o chofar, chama-se Zikkron teru ah. Digamos que o som do chofar, o zikhronot, é o que existe da lembrança ligada a esse som". Id. Livro 10, A angústia, Rio de Janeiro: Zahar, 2005, p. 274.

6 "Visto por esse prisma, que se completa com a aproximação das diversas ocasiões em que ele nos é assinalado e entre efetivamente em funcionamento, esse chofar parece realmente ser, diz-nos Reik, a voz de Javé, a voz do próprio Deus". Ibid., p. 272

7 John Rickman citado por Adam Phillips. La meilleure des vies. Paris, éd.de L'Olivier, 2013, p.26

${ }^{8}$ Zular, Roberto. O ouvido da serpente: algumas considerações a partir de duas estrofes de Esboço de uma serpente de Paul Valéry. Passos e, Cleusa Rios P. Rosenbaum, Yudith (orgs). Interpretações: crítica literária e psicanálise. São Paulo, Áteliê ed., 2014, p.222

9 Willemart. Psicanálise e teoria literária (o tempo lógica e as rodas da escritura e da leitura). São Paulo, Perspectiva, 2014, p. 17

10 "Foi somente na análise e desde então que fiz frente á luta com o anjo ... esta luta é sempre noturna porque não sou capaz, ou ainda não, conceber nem aperceber o divino na luz." Bauchau. Journal d'Antigone (1989-1997). Arles: Actes Sud, 1999, p. 120 e 371-372

11 Proust, Marcel. No Caminho de Swann. Em Busca do Tempo Perdido.. (Trad. Mario Quintana). São Paulo, Globo S.A, 2006. vol. I. p. 295

12 Willemart. À procura de um ritmo no início de Combray. Psicanalise e teoria literária. São Paulo, Perspectiva, 2014, p. 146.

${ }^{13} \mathrm{O}$ dancarino é levado fora deste baixo mundo. Casando com a música, ele abandona a liberdade de seus atos, e no entanto, ele age numa liberdade mais alta e mais lúcida. No rigor do ritmo que o guia, ele se sente abrigado e nesta quietude coberta, ele sente subir nele um grande soltar dos laços terrestres. É assim que a música traz a ordem e a unidade neste embaralhamento e a condição caótica da vida.Abolindo o tempo, ela abole a morte, embora a fazendo renascer ao mesmo tempo de novo, a dada medida, mesmo nas medidas deste morne e interminável pot-pourri que ressoa neste momento e que, sob o nome de De todas as margens da música, enumera um sucessão multicolore dos estribilhos patrióticos e das dancas inimigas, como o cake-walk, a matchicha e o tango. Broch, Hermann. Les somnambules. Paris, Gallimard, 1990, p. 570.

14 Marcel Proust. Albertine disparue. (edição original da última versão revista pelo autor, estabelecida por Nathalie Mauriac e Eienne Wolff.) Paris, Grasset, 1987

15 "algo irritante, um obstáculo, sabotagem para que algo acontece". Phillips, Adam. Trois capacités négatives. Paris, Ed. de l'Olivier, 2009, p. 16.

16 Passos, Cleusa Rios P.. O fantástico e as formas do unheilich: Borges e seus duplos. Passos, Cleusa Rios P. e Rosenbaum, Yudith (orgs). Interpretações: crítica literária e psicanálise. São Paulo, Ateliê ed., 2014, p. 124.

${ }^{17} \mathrm{http}: / /$ gallica.bnf.fr/ark:/12148/btv1b60001231/f19.image.r=fonds\%20proust\%20NAF\%2016668.langFR

${ }^{18}$ Salles, Cecília Almeida. Redes da criação. Vinhedo, Editora Horizonte, 2006

${ }^{19}$ Leriche, Francoise. Vinteuil ou le révélateur de transformations esthétiques dans la Genèse de la Recherche. Bullein d'informations proustiennes. Paris, éd. ENS, 1985 ,n*16, p.27

${ }^{20}$ Phillips, Adam. La meilleure des vies, p.67 